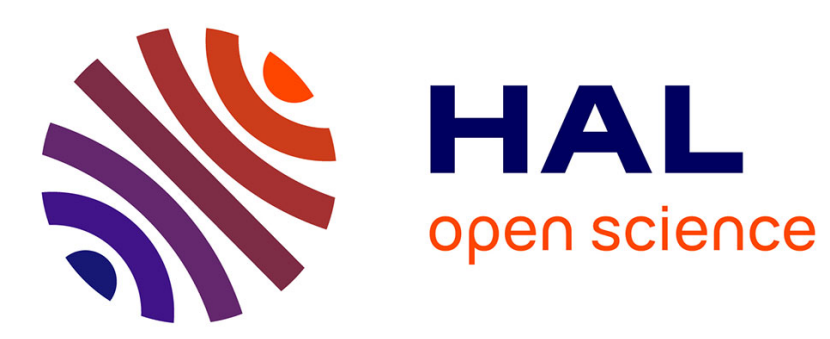

\title{
Sizing of a stand-alone microgrid considering electric power, cooling/heating and hydrogen
}

Bei Li, Robin Roche, Abdellatif Miraoui

\section{To cite this version:}

Bei Li, Robin Roche, Abdellatif Miraoui. Sizing of a stand-alone microgrid considering electric power, cooling/heating and hydrogen. PowerTech, Jun 2017, Manchester, United Kingdom. hal-02131010

\author{
HAL Id: hal-02131010 \\ https://hal.science/hal-02131010
}

Submitted on 16 May 2019

HAL is a multi-disciplinary open access archive for the deposit and dissemination of scientific research documents, whether they are published or not. The documents may come from teaching and research institutions in France or abroad, or from public or private research centers.
L'archive ouverte pluridisciplinaire HAL, est destinée au dépôt et à la diffusion de documents scientifiques de niveau recherche, publiés ou non, émanant des établissements d'enseignement et de recherche français ou étrangers, des laboratoires publics ou privés. 


\title{
Sizing of a stand-alone microgrid considering electric power, cooling/heating and hydrogen
}

\author{
Bei Li, Robin Roche and Abdellatif Miraoui \\ FEMTO-ST, CNRS, Univ. Bourgogne Franche-Comte, UTBM \\ FCLAB, CNRS, Univ. Bourgogne Franche-Comte \\ rue Thierry Mieg, F-90010 Belfort Cedex, France bei.li@utbm.fr
}

\begin{abstract}
Microgrids are small-scale power systems that include local generation and storage units to serve their loads. The effectiveness of such systems depends on both sizing and operations, that need to be efficient to minimize costs while ensuring reliable power delivery. In this paper, we build a stand-alone microgrid while considering not only electric power, but also cooling, heating, and hydrogen consumption. A unit commitment algorithm, formulated as a mixed integer linear programming problem, is used to determine the best operation strategy of the system. A genetic algorithm is used to search for the best size of each component. Results show the feasibility of the proposed sizing method.

Index Terms - sizing, energy management, microgrid (MG), multi-energy system, unit commitment
\end{abstract}

\section{INTRODUCTION}

As natural disasters (e.g., hurricanes, storms, floods, earthquakes) often result in power cuts or blackouts [1] in traditional centralized systems, distributed generation (DG) provides an alternative solution. DG enables powering loads using local resources, which reduces the dependence on the rest of the system. Microgrids use DG to form small scale power systems, capable of operating in stand-alone mode. While conventional sources, such as diesel gensets, are commonly used, drawbacks include the emissions resulting from their operation, as well as dependence on fuel supply [1], [2]. Renewable energy emerges as another option, where direct emissions are non existent, as well as fuel dependence.

In this work, we consider microgrids with multiple energies, including electric, thermal and hydrogen loads (Fig. 1). Combined heat and power (CHP) plants are typically efficient and economical, and have applications in the residential and industrial sectors, especially when multiple energies are considered [3]-[5]. We also consider loads to be cooled by an air conditioner and an absorption heat chiller, and loads to be heated by solar heat, an electric heat boiler. Electric loads are powered by PV panels, and a battery. Finally, a fuel cell is used as a CHP source for both electricity and heat, and an electrolyzer is used to produce hydrogen, which is then stored in tanks. Similarly, heat storage is used.

Multiple energy systems are a key solution to evolve toward a cleaner and affordable energy supply systems [6]. But the sizing and operation of such complex systems, with interdependent layers (one for each type of energy: electricity, heat or hydrogen), seems non trivial. For example, oversizing components will result in higher capital and possibly operation

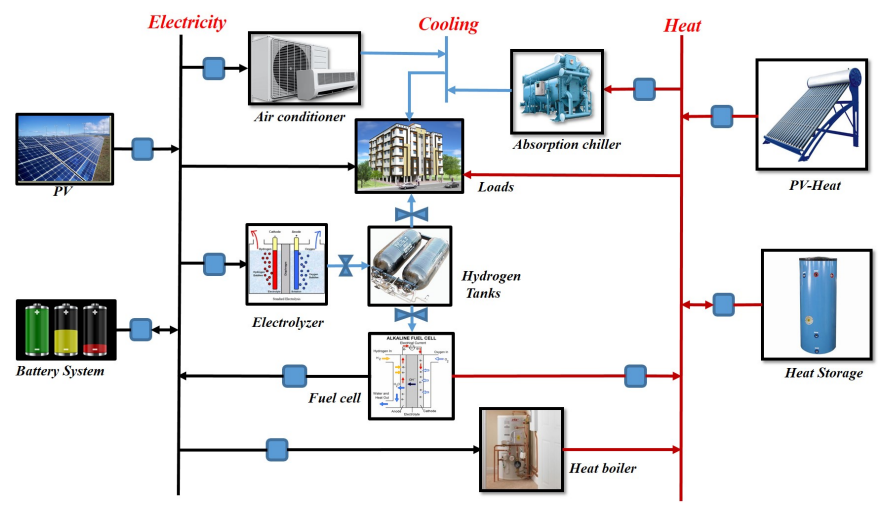

Fig. 1. Stand-alone microgrid architecture.

costs, while undersizing may result in generation curtailment or load shedding. Adequate operation is also required to avoid curtailment and shedding, while minimizing costs. This means that the sizing results are affected not only by the architecture of system, but also by the operation strategy [7]. Depending on how components are used, their necessary capacity may vary greatly, which in turn impacts sizing results.

In this paper, we decompose the sizing problem into a leader-follower problem. The follower problem, namely, the energy management strategy, is formulated as a unit commitment problem, in the form of a mixed integer liner problem. We use mixed integer linear programming (MILP) to obtain the optimal operation strategy. The leader problem, namely, the sizing problem, uses an evolutionary algorithm (EA) to search for the best sizing values [8].

The remainder of this paper is organized as follows. Section II introduces related work. Section III describes the model of microgrid components, Section IV the operation strategy, Section V the sizing solution, and Section VI the simulation results. Finally, Section VII concludes the paper.

\section{RELATED WORK}

In this section, we review related works about the optimal sizing problem of microgrids. Optimal sizing problem solutions may be divided into two intricate parts: a) to determine an operation strategy to control power flows in the system; b) to search for the best sizing values of each component, considering this operation strategy. In the literature, related 
works using this approach may be categorized into three categories: 1) papers using sizing values chosen from a discrete set, and where the operation strategy is described using mixed integer programming (MIP) [9]-[12]; 2) papers where sizing values are chosen using an EA and where the operation strategy is based on rules [13], [14]; and 3) papers where sizing values are decided using an EA, and where the operation strategy is described using MIP [8], [15]-[19].

For the first category, in [9], authors present a deterministic linear programming (LP) model to obtain the optimal size of a residential CHP, and the objective function is to minimize the annual cost of the system. A constant ratio is used to represent the relation between electricity output and heat output. In [10], authors also present an LP algorithm to optimize the operation of smart hybrid renewable energy communities. In [11], authors present a mixed integer nonlinear programming (MINP) model for optimal sizing of a residential CHP system, aiming to minimize the overall cost. In [12], authors present a MINP model to solve the sizing problem for an active distribution system.

For the second category, the authors in [13], [14] compare different heuristic techniques to find the optimal sizing of microgrids, where the objective function is the total annual cost. Multiple similar papers may be found in the literature.

In [15], authors present a leader-follower optimization method for microgrid planning in electrical power systems. The leader problem optimizes the planning decisions for microgrids and the main grid, and then with the proposed plan, the short-term and economic operation subproblems are then solved. In [16], authors present a microgrid planning model. This problem is decomposed into an investment master problem and an operation subproblem. These problems are linked via the benders decomposition method. In [17], authors present a bi-level program for islanded microgrids including compressed air energy storage. The upper level problem is solved using a genetic algorithm (GA), and the lower level problem is solved using an MILP technique. [18] presents a multi-objective model-based optimization approach for the optimal sizing of all components. A GA and the non-linear mesh adaptive direct search method are used to decide the sizing values, where the objectives are the capital expenditure, the levelised cost of energy and emissions. The optimal control problem is formulated as a MINLP, and solved using discrete dynamic programming. [19] presents a two-stage optimal planning and design method for a CCHP microgrid system. In the first stage, a multi-objective genetic algorithm based on NSGA-II is applied to solve the optimal design problem. The objective function is to minimize the total net present cost and carbon dioxide emissions. In the second stage, an MILP algorithm was used to solve the optimal dispatching problem, where the objective function is to minimize the operation cost.

Based on the above researches, we can conclude that the sizing problem is a non-convex combinatorial co-optimization problem, which requires suitable algorithms. Methods relying on rules are too complex for such a multi-energy system. In our previous paper [8], a co-optimization method com- bining an EA and MILP was used to size a full-electric islanded microgrid. In this paper, we expand our previous work and focus on a hydrogen-storage-based multi-energy islanded microgrid system, and research about the optimal sizing strategy. Although [18], [19] also have considered cooptimization methods, the contribution of this paper is focused on providing a sizing solution capable to consider electricity, heat, cooling and hydrogen load demands at the same time. Moreover, others papers not focused hydrogen storage for the sizing of multi-energy islanded microgrid systems.

\section{COMPONENTS MODELS}

In this paper, the stand-alone microgrid contains nine components shown in Fig. 1. Due to page limits, the models introduced in our previous paper [8] (PV panels, battery, fuel cell, electrolyzer, and hydrogen tanks) are re-used and not presented again in this paper. The models for the new components are introduced below.

Due to the high time constants of most of the selected models, static power converters are neglected and simple models are used.

\section{A. Solar generation components}

For the solar heating system, the power output is computed with [20]: $Q_{s h}=N_{s h} \cdot \eta_{s h} \cdot G_{A}$. where $N_{s h}$ is the area of the heating system, and $\eta_{s h}$ its efficiency.

\section{B. Battery}

The state-of-charge (SOC) is used to represent the state of the battery as follows:

$$
\begin{aligned}
S O C(t)= & S O C(t-\Delta t) \\
& +\frac{\eta_{c h} \cdot P_{c h}(t) \cdot \Delta t}{C B}-\frac{P_{d i s}(t) \cdot \Delta t}{C B}
\end{aligned}
$$

where $\eta_{c h}$ is the charging efficiency, $P_{c h}(t)$ the charging power, $P_{d i s}(t)$ the discharging power, $\Delta t$ the interval time, and $C B$ the capacity of the battery.

\section{Hydrogen tank model}

A hydrogen tank is used to store the hydrogen produced by the electrolyzer, as well as supply hydrogen to the fuel cell. We use the level of hydrogen $(\mathrm{LOH})$ to represent the state of the tank:

$$
L O H(t)=L O H(t-\Delta t)+\dot{n}_{H 2}^{p r o} \cdot \Delta t-\dot{n}_{H 2}^{c o n} \cdot \Delta t-L_{H_{2}}(t)
$$

where $L_{H_{2}}(t)$ is the hydrogen load demand. Then, using the law of perfect gases $(P V=n R T)$, the volume of the tanks can be calculated.

\section{Thermal components}

We use simple models for the thermal components. A heat boiler (HB) uses electricity to produce heat as follows [12]: $Q_{h b}=\eta_{h b} \cdot P_{h b}$, where $P_{h b}$ is the input power, $\eta_{h b}$ the efficiency, and $Q_{h b}$ the output heat.

An air conditioner is used to cool air [12]: $C_{a c}=\eta_{a c} \cdot P_{a c}$, where $P_{a c}$ is the input power, $\eta_{a c}$ the efficiency, and $C_{a c}$ the cooling output cooling power. 
Similarly, the absorption heat chiller (AHC) uses heat to produce cooling, so [12]: $C_{a h c}=\eta_{a h c} \cdot Q_{a h c}$, where $Q_{a h c}$ is the input heat, $\eta_{a h c}$ the efficiency, and $C_{a h c}$ the output cooling power.

Finally, the state of the heat storage system is represented by the amount of heat stored [21]:

$$
H S(t)=H S(t-\Delta t)+\eta_{h s}^{c h} \cdot Q_{h s}^{c h} \cdot \Delta t-\frac{Q_{h s}^{d i s}}{\eta_{h s}^{d i s}} \cdot \Delta t
$$

where $H S(t)$ is the stored heat at time $t . \eta_{h s}^{c h}$ and $\eta_{h s}^{d i s}$ are the charge and discharge efficiency, respectively.

\section{UC OPTIMIZATION OPERATION STRATEGY}

We now describe the strategy used to control the different microgrid components. In this paper we adopt a UC optimization method formed as an MILP to optimize system operation. The concept of UC optimization applied to this case is to use the above models to optimize operations using predicted information. In this case, the predicted information corresponds to solar radiation and loads. The controller choses the optimal operating point of each component to minimize a cost function while enforcing all constraints.

\section{A. Cost function}

In order to achieve economical operation at each time step, we need to assess the utilization cost of storage elements, as well as all other auxiliary components. For the battery storage system (BSS), the utilization cost of charge and discharge are indroduced as follows [22]:

$$
B_{\text {cost }}^{\text {ch, dis }}(t)=\frac{C_{b a}^{i n v}}{2 \cdot N_{\text {cycles }}} \cdot\left(P_{\text {ch }}(t)+P_{\text {dis }}(t)\right)
$$

where $C_{b a}^{i n v}$ is the investment cost of the battery, and $N_{c y c l e s}$ is the number of cycles over the lifetime.

The hydrogen storage system (HSS) combines an electrolyzer, a fuel cell and hydrogen tanks. As for the BSS, its utilization cost can be computed as follows [22]:

$H_{\text {cost }}^{\text {ele }}(t)=\left(\frac{C_{\text {ele }}^{\text {inv }}}{N_{\text {hours }}^{\text {ele }}}+C_{\text {ele }}^{\text {o\&m }}\right) \cdot \delta_{\text {ele }}(t)+C_{\text {ele }}^{\text {startup }} \cdot \Delta \delta_{\text {ele }}(t)$

$H_{\text {cost }}^{f c}(t)=\left(\frac{C_{f c}^{i n v}}{N_{\text {hours }}^{f c}}+C_{f c}^{o \& m}\right) \cdot \delta_{f c}(t)+C_{f c}^{\text {startup }} \cdot \Delta \delta_{f c}(t)$

where $C_{\text {ele }}^{i n v}, C_{f c}^{i n v}$ are the investment costs of the electrolyzer and the fuel cell, $C_{\text {ele }}^{o \& m}$ and $C_{f c}^{o \& m}$ the operation and maintenance costs, and $C_{\text {ele }}^{\text {startup }}$ and $C_{f c}^{\text {startup }}$ the startup costs. Variables $\delta_{\text {ele }}(t)$ and $\delta_{f c}(t)$ are the state of the electrolyzer and the fuel cell. When a unit is on, $\delta_{i}(t)=$ $1, i=\{e l e, f c\}$, otherwise it is set to 0 . Equation $\Delta \delta_{i}(t)=$ $\max \left\{\delta_{i}(t)-\delta_{i}(t-1), 0\right\}, i=\{e l e, f c\}$ represents whether the unit started or not.
We use a similar approach for thermal components. The heat boiler, air conditioner and absoption heat chiller operation costs are given by [11]:

$$
\begin{aligned}
H B_{\text {cost }}(t) & =\frac{C_{h b}^{i n v}}{N_{l i f e}^{h b}} \cdot P_{h b}(t) \\
A C_{\text {cost }}(t) & =\frac{C_{a c}^{i n v}}{N_{l i f e}^{a c}} \cdot P_{a c}(t) \\
A H C_{\text {cost }}(t) & =\frac{C_{a h c}^{i n v}}{N_{l i f e}^{a h c}} \cdot P_{a h c}(t)
\end{aligned}
$$

In the above equations, $C^{i n v}$ and $N_{i \text { ife }}$ are the investment cost and life time of each component. For the heat storage system, the operation cost is:

$$
H S_{\text {cost }}(t)=\frac{C_{h s}^{i n v}}{N_{\text {life }}^{h s}} \cdot\left(Q_{h s}^{c h}(t)+Q_{h s}^{\text {dis }}(t)\right)
$$

\section{B. Operation cost function}

The optimization tries to minimize overall operation costs over a given horizon of $T$ time steps. The total cost function is then as follows:

$$
\begin{array}{r}
C_{\text {op }}=\sum_{t=1}^{T}\left\{B_{\text {cost }}^{\text {ch, dis }}(t)+H_{\text {cost }}^{\text {ele }}(t)+H_{\text {cost }}^{f c}(t)+H B_{\text {cost }}(t)\right. \\
+A C_{\text {cost }}(t)+A H C_{\text {cost }}(t)+H S_{\text {cost }}(t) \\
+\alpha \cdot\left(L S_{\text {cooling }}(t)+L S_{\text {heat }}(t)+L S_{\text {power }}(t)\right. \\
\left.+\beta \cdot\left(\text { cut }_{P V}(t)+\text { cut }_{\text {solar }}(t)\right)\right\}
\end{array}
$$

where $L S_{m}(t)$ with $m=$ cooling, heat, power $\}$ is the shed cooling, heat and power loads, and $c u t_{n}(t)$ with $n=$ $\{\mathrm{PV}$, solar $\}$ are the curtailed PV power and solar heating. $\alpha$ and $\beta$ are penalty values for load shedding and curtailed power.

\section{Constraints}

The stand-alone microgrid is subject to the following constraints, with $i=\{e l, f c\}$ and $j=\{e l, f c$, bach, badis, $h b, a c, a h c, h s c h, h s d i s\}$. Variables $\gamma_{1}^{j}$ and $\gamma_{2}^{j}$ are constant real values used to set the minimum and maximum power range of each component (below, we use the following notation: $\left.Z_{j}(t)=\delta_{j}(k) \cdot P_{j}(t)\right)$ :

$$
\begin{aligned}
\gamma_{1}^{j} P_{j}^{\text {min }} & \leq P_{j}(t) \leq \gamma_{2}^{j} P_{j}^{\max } \\
\delta_{j}(k) \cdot \gamma_{1}^{j} P_{j}^{\text {min }} & \leq Z_{j}(t)=\delta_{j}(k) \cdot P_{j}(t) \leq \delta_{j}(k) \cdot \gamma_{2}^{j} P_{j}^{\max } \\
Z_{j}(t) & \leq P_{j}(t)-\left(1-\delta_{j}(t)\right) \cdot \gamma_{1}^{j} P_{j}^{\min } \\
Z_{j}(t) & \geq P_{j}(t)-\left(1-\delta_{j}(t)\right) \cdot \gamma_{2}^{j} P_{j}^{\max } \\
& \delta_{\text {ele }}(t)+\delta_{f c}(t) \leq 1 \\
& \delta_{\text {bach }}(t)+\delta_{\text {badis }}(t) \leq 1 \\
& \delta_{h s c h}(t)+\delta_{\text {hsdis }}(t) \leq 1
\end{aligned}
$$

Equation (15) means that the fuel cell and the electrolyzer cannot start up at the same time. The BSS and heat storage system also cannot charge and discharge at the same time. 
$\Delta \delta_{i}(t)=\max \left\{\delta_{i}(t)-\delta_{i}(t-1), 0\right\}$ can be expressed as $\Delta \delta_{i}(t)=\delta_{i}(t) \cdot\left(1-\delta_{i}(t-1)\right)$. Then, using [23], the above nonlinear equations system can be transformed into the following linear constraints:

$$
\begin{aligned}
& -\delta_{i}(t)+\Delta \delta_{i}(t) \leq 0 \\
& -\left(1-\delta_{i}(t-1)\right)+\Delta \delta_{i}(t) \leq 0 \\
& \delta_{i}(t)+\left(1-\delta_{i}(t-1)\right)-\Delta \delta_{i}(t) \leq 1
\end{aligned}
$$

The power balance equation is written as:

$$
\begin{aligned}
& P V(t)-\operatorname{cut}_{P V}(t)-\left(L_{\text {power }}(t)-L S_{\text {power }}(t)\right)=Z_{\text {ele }}(t) \\
& -Z_{f c}(t)+Z_{\text {bach }}(t)-Z_{\text {badis }}(t)+Z_{a c}(t)+Z_{h b}(t)
\end{aligned}
$$

Similarly, for the heat and cooling balance equations:

$$
\begin{aligned}
& Q_{s h}(t)-\text { cut }_{\text {solar }}(t)-\left(L_{\text {heat }}(t)-L S_{\text {heat }}(t)\right)+Q_{f c}(t) \\
& +Q_{h b}(t)=Q_{h s c h}(t)-Q_{h s d i s}(t)+Q_{a h c}(t) \\
& C_{a c}(t)+C_{a h c}(t)=L_{\text {cooling }}(t)-L S_{\text {cooling }}(t)
\end{aligned}
$$

Finally, for the SOC, LOH and HS constraints:

$$
\begin{aligned}
& S O C_{\text {min }} \leq S O C(t) \leq S O C_{\text {max }} \\
& L O H_{\text {min }} \leq L O H(t) \leq L O H_{\text {max }} \\
& H S_{\text {min }} \leq H S(t) \leq H S_{\text {max }}
\end{aligned}
$$

In summary, with the UC control strategy, the problem can be formulated as:

$$
\begin{aligned}
& \min _{\widetilde{S}}\left\{C_{o p}\right\} \\
& \text { s.t. }(1),(2),(3),(12)-(19)
\end{aligned}
$$

where $\widetilde{S}$ is the set of variables.

\section{SIZING SOLUTIONS}

Based on the above section, we can describe the power flow in the microgrid system. Our goal is to compute the optimal size value of each component, namely, $N_{P V}, N_{s h}, C B, P_{f c}^{\max }, P_{e l}^{\max }, V_{H_{2}}^{\max }, P_{h b}^{\max }, P_{a c}^{\max }, Q_{a h c}^{\max }$, $H S_{\text {max }}$. Let set $U$ represent these size variables. Then the sizing problem is to minimze $F(U)$, with $F($.) the total cost function introduced in the following.

The total capital cost corresponds to the cost of buying the equipment, and is given by:

$$
\begin{array}{r}
C_{\text {cap }}=C R F \cdot\left(N_{P V} \cdot C_{P V}^{i n v}+N_{s h} \cdot C_{s h}^{i n v}+P_{f c}^{\max } \cdot C_{f c}^{i n v}\right. \\
+P_{e l}^{\max } \cdot C_{e l e}^{i n v}+V_{H_{2}}^{\max } \cdot C_{t a n k}^{i n v}+C_{b a t} \cdot C_{b a t}^{i n v}+P_{h b}^{\max } \cdot C_{h b}^{i n v} \\
\left.+P_{a c}^{\max } \cdot C_{a c}^{i n v}+P_{a h c}^{\max } \cdot C_{a h c}^{i n v}+H S_{\max } \cdot C_{h s}^{i n v}\right)
\end{array}
$$

where $C^{i n v}$ variables represent the price of each component. $C R F=\frac{r(1+r)^{n_{i n v}}}{(1+r)^{n} \text { inv }-1}$ is the capital recovery factor (CRF) [14], $r$ is the real interest rate and $n_{i n v}$ is the expected life span of the microgrid.

The total cost function $F($.$) is thus: F=C_{\text {cap }}+C_{\text {op }}$.
Finally, the overall problem can be formulated as:

$$
\begin{aligned}
& \min _{U \in \mathbf{U}}\left\{C_{\text {cap }}+\min _{U^{*}, \widetilde{S}}\left\{C_{\text {op }}\right\}\right\} \\
& \text { s.t. }(1),(2),(3),(12)-(19)
\end{aligned}
$$

A genetic algorithm (GA) is used to search for the best sizing values.

\section{Simulation RESUlts}

\section{A. System setup}

For the fuel cell, the electrolyzer and the heat boiler, we set $\gamma_{1}^{f c, e l e}=0.5, \gamma_{1}^{h b}=0, \gamma_{2}^{f c, e l e, h b}=1$; for the air conditioner, $\gamma_{1}^{a c}=0.1, \gamma_{2}^{a c}=0.9$; for the absorption heat chiller, $\gamma_{1}^{a h c}=$ $0, \gamma_{2}^{a h c}=0.9$; for the battery, $S O C_{\min }=0.5, S O C_{\min }=$ 0.9 ; for the hydrogen tanks, $L O H_{\min }=1 \mathrm{~N} . \mathrm{m}^{3}$; for the heat storage, $H S_{\text {min }}=0$; and $\alpha=\beta=10^{10}$. Here, the penalty values are chosen large enough to guarantee that no load shedding and curtailed power will occur. The cost parameters are adopted from [8], [12], [24]. The model is implemented in MATLAB and solved with YALMIP [25] and Gurobi. Simulations were run on a computer with an Intel Xeon CPU E3-1220@3.1GHz.

Load demand data (for cooling, heat, electric power and hydrogen) and solar radiation are obtainted from a research building, located in Belfort, France. The corresponding profiles (one day average) are shown in Figs. 2 and 3. In our simulation, we adopt 12 days with one hour-resolution data. These 12 days correspond to the electricity load demand peak day, heating load demand peak day, and the cooling load demand peak day in the four seasons. Hydrogen is used to run FC research experiments. Heating and cooling loads are calculated based on a building thermal model.

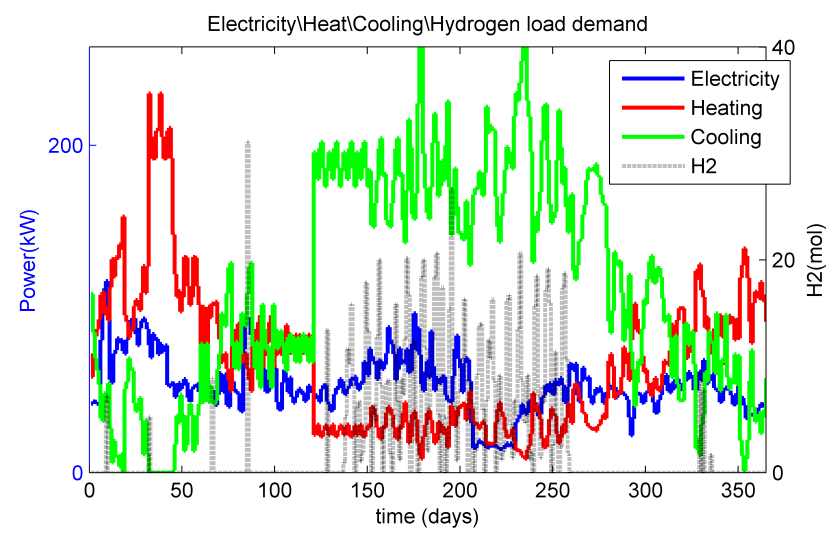

Fig. 2. Cooling/heat/electricity demand profiles (one day average).

\section{B. GA-based sizing results}

A GA [8] is based on natural selection processes similar to biological evolution. It uses tools such as mutations, crossover and selection to generate candidate solutions. In our simulation, the population size is 20 , and the maximum number of iterations is 100 . Each population gives the sizing values of each component, then the MILP operation optimization is run. 


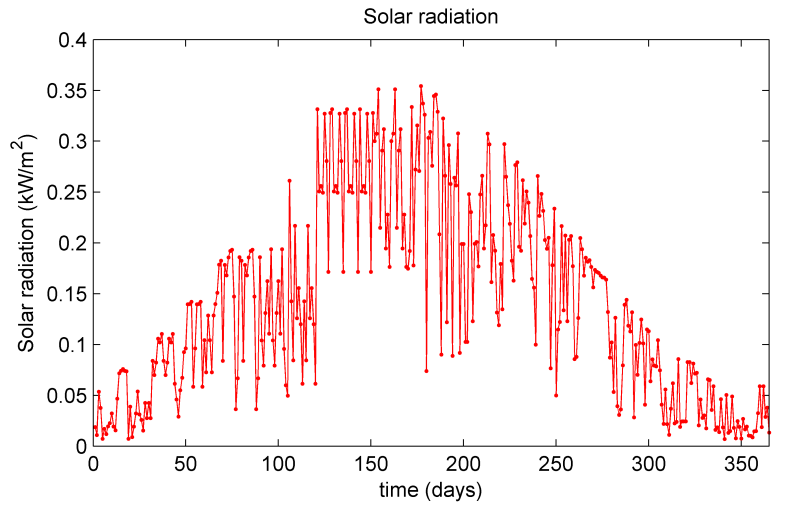

Fig. 3. Daily average solar radiation profile.

Based on these results, the population is then updated. The total simulation time is about 1 hour.

The obtained optimal size values are: $N_{P V}=327, N_{s h}=$ $43 \mathrm{~m}^{2}, C B=735 \mathrm{kWh}, P_{f c}^{\max }=131 \mathrm{~kW}, P_{e l}^{\max }=690 \mathrm{~kW}$, $\Delta V_{H_{2}}=84865 \mathrm{Nm}^{3}, P_{h b}^{\max }=283 \mathrm{~kW}, P_{a c}^{\max }=159 \mathrm{~kW}$, $Q_{a h c}^{\max }=686 \mathrm{~kW}, \Delta H S_{\max }=3000 \mathrm{kWh}$.

Here $\Delta V_{H_{2}}=\max \left\{\Delta V_{H_{2}}^{r d}\right\}, r d=\{1, \ldots, 12\}$, where $r d$ represents the 12 days. $\Delta V_{H_{2}}^{r d}=V_{\max }^{r d}-V_{\min }^{r d}$ represents the hydrogen level change in tanks for day $r d$. Similarly, $\Delta H S_{\max }=\max \left\{\Delta H S^{r d}\right\}, r d=\{1, \ldots, 12\}$, where $\Delta H S^{r d}=H S_{\max }^{r d}-H S_{\min }^{r d}$ represents the heat level change in the heat storage system for day $r d$.

Based on the above sizing values, we can compute the scheduling results by running the MILP algorithm. We run it for scheduling one day (here, the cooling peak load demand day in May). Fig. 4 shows the resulting electric power schedule. We observe that the HSS is the main storage system, with slow variations in output, while the BSS only serves as an auxiliary storage system, with shorter and more dynamic charge and discharge periods. The FC generates more electricity than the electric load demand, in order to supply the heating and cooling loads. On the other hand, the AC uses electricity to produce cool air, and the HB uses electricity to produce heat. We also observe that the curtailed PV power is non existent, as is load shedding, which tends to indicate that the sizing is sufficient.

Fig. 5 shows the heating power schedule. The heat boiler and the fuel cell supply most of the heating load demand. The heat boiler uses electricity to heat water. This heat can be stored, and can also be used in the absorption chiller. The FC also generates heat, which can be transferred to rooms through pumps. The AHC uses heat to produce cooling, and operates as load. Similarly, Fig. 6 shows the cooling power schedule. The absorption heat chiller and the air conditioner supply all the cooling load.

Regarding storage, Fig. 7 shows the change in SOC and LOH. Fig. 8 shows the change in stored heat. We observe that the hydrogen storage system operates as the main electricity storage system. A similar comment can be made for the heat storage system. When energy (electricity/heating) in each bus is unbalanced, the storage system is used to balance the power flow. Due to operation of the heat boiler, electric energy can also be converted to heat.

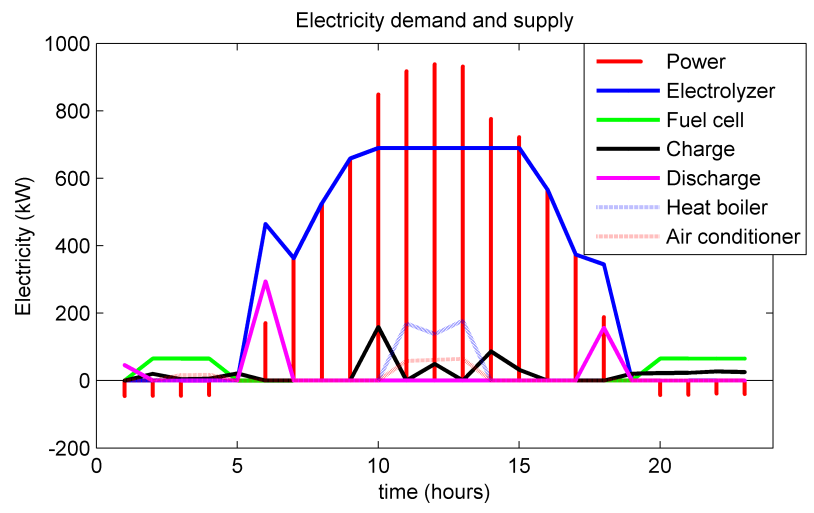

Fig. 4. Electric power schedule (power means PV output minus electricity load demand; charge/discharge curves are for the battery).

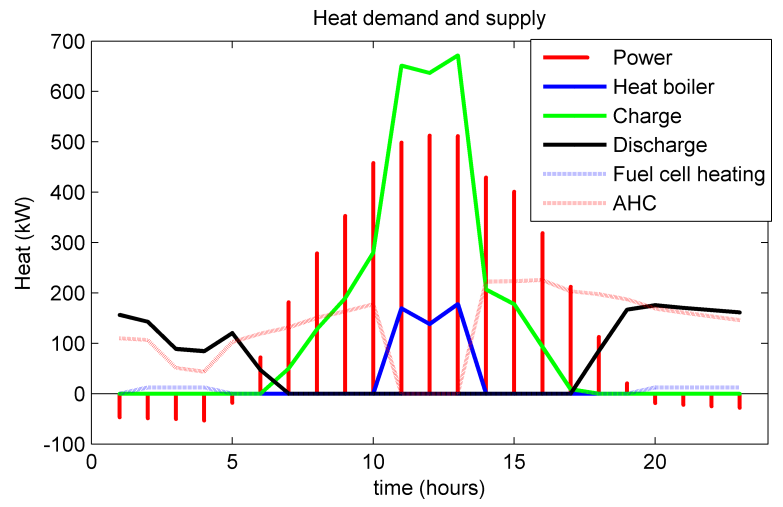

Fig. 5. Heat power schedule (power means solar output minus heat load demand; charge/discharge curves are for the heat storage system).

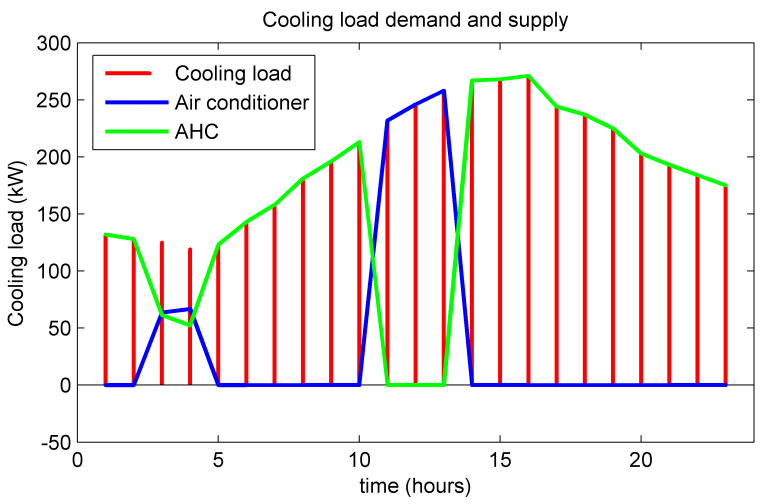

Fig. 6. Cooling power schedule.

\section{CONCLUSION}

In this paper, we introduced a strategy for sizing a standalone microgrid combining cooling, heat, electric power and hydrogen loads. The UC optimization method is used for 


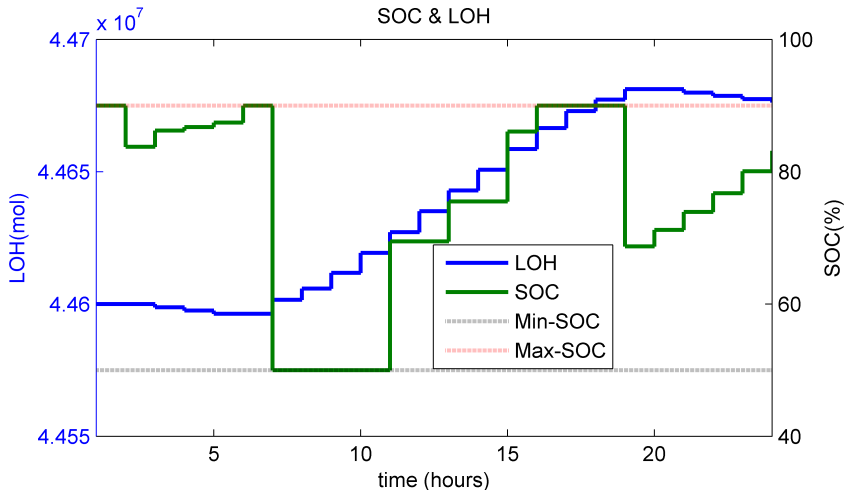

Fig. 7. LOH and SOC.

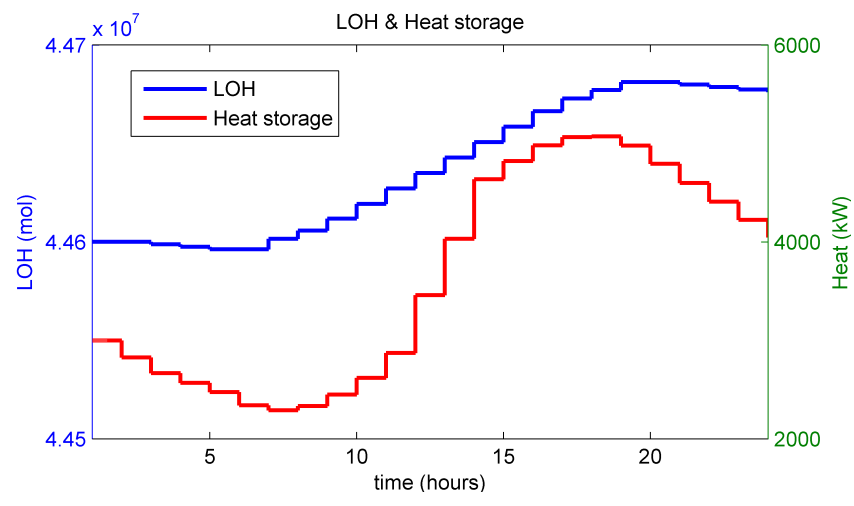

Fig. 8. LOH and stored heat.

defining the operation strategy, which aims at minimizing the operation cost through an MILP algorithm. A GA is used to compute the sizing value of each component, aiming to minimize the total cost. The results show that the optimal size value and operation algorithms are capable of scheduling multiple components and managing flows from different natures (heat, electricity and hydrogen). Future work will focus on longer validation periods, as well as considering the dynamics of components, especially for storage.

\section{REFERENCES}

[1] Y. Wang, C. Chen, J. Wang, and R. Baldick, "Research on resilience of power systems under natural disasters - a review," IEEE Transactions on Power Systems, vol. 31, no. 2, pp. 1604-1613, March 2016.

[2] C. Chen, J. Wang, F. Qiu, and D. Zhao, "Resilient distribution system by microgrids formation after natural disasters," IEEE Transactions on Smart Grid, vol. 7, no. 2, pp. 958-966, March 2016.

[3] D. Wu and R. Wang, "Combined cooling, heating and power: a review," progress in energy and combustion science, vol. 32, no. 5, pp. 459-495, 2006.

[4] M. Liu, Y. Shi, and F. Fang, "Combined cooling, heating and power systems: A survey," Renewable and Sustainable Energy Reviews, vol. 35, pp. 1-22, 2014.

[5] W. Gu, Z. Wu, R. Bo, W. Liu, G. Zhou, W. Chen, and Z. Wu, "Modeling, planning and optimal energy management of combined cooling, heating and power microgrid: A review,' International Journal of Electrical Power \& Energy Systems, vol. 54, pp. 26-37, 2014.

[6] P. Mancarella, "Mes (multi-energy systems): An overview of concepts and evaluation models," Energy, vol. 65, pp. 1-17, 2014.
[7] R. P. Menon, M. Paolone, and F. Maréchal, "Study of optimal design of polygeneration systems in optimal control strategies," Energy, vol. 55, pp. 134-141, 2013.

[8] B. Li, R. Roche, and A. Miraoui, "Microgrid sizing with combined evolutionary algorithm and milp unit commitment," Applied Energy, vol. 188, pp. 547-562, 2017.

[9] O. Shaneb, G. Coates, and P. Taylor, "Sizing of residential $\mu \mathrm{chp}$ systems," Energy and Buildings, vol. 43, no. 8, pp. 1991-2001, 2011.

[10] H. Wang, E. Abdollahi, R. Lahdelma, W. Jiao, and Z. Zhou, "Modelling and optimization of the smart hybrid renewable energy for communities (shrec)," Renewable Energy, vol. 84, pp. 114-123, 2015.

[11] H. Ren, W. Gao, and Y. Ruan, "Optimal sizing for residential chp system," Applied Thermal Engineering, vol. 28, no. 5, pp. 514-523, 2008.

[12] S. Xinwei, H. Yingduo, Z. Shouzhen, J. Zheng, L. Qingsheng, and N. Jing, "Comprehensive power-supply planning for active distribution system considering cooling, heating and power load balance," Journal of Modern Power Systems and Clean Energy, vol. 3, no. 4, pp. 485-493, 2015.

[13] A. Maleki and A. Askarzadeh, "Comparative study of artificial intelligence techniques for sizing of a hydrogen-based stand-alone photovoltaic/wind hybrid system," international journal of hydrogen energy, vol. 39, no. 19, pp. 9973-9984, 2014.

[14] A. Maleki and F. Pourfayaz, "Optimal sizing of autonomous hybrid photovoltaic/wind/battery power system with lpsp technology by using evolutionary algorithms," Solar Energy, vol. 115, pp. 471-483, 2015.

[15] A. Khodaei and M. Shahidehpour, "Microgrid-based co-optimization of generation and transmission planning in power systems," IEEE transactions on power systems, vol. 28, no. 2, pp. 1582-1590, 2013.

[16] A. Khodaei, S. Bahramirad, and M. Shahidehpour, "Microgrid planning under uncertainty," IEEE Transactions on Power Systems, vol. 30, no. 5, pp. 2417-2425, 2015.

[17] J. Zhang, K.-J. Li, M. Wang, W.-J. Lee, and H. Gao, "A bi-level program for the planning of an islanded microgrid including caes," in Industry Applications Society Annual Meeting, 2015 IEEE. IEEE, 2015, pp. $1-8$.

[18] J. Sachs and O. Sawodny, "Multi-objective three stage design optimization for island microgrids," Applied Energy, vol. 165, pp. 789-800, 2016

[19] L. Guo, W. Liu, J. Cai, B. Hong, and C. Wang, "A two-stage optimal planning and design method for combined cooling, heat and power microgrid system," Energy Conversion and Management, vol. 74, pp. 433-445, 2013

[20] M. Lazaar, S. Bouadila, S. Kooli, and A. Farhat, "Comparative study of conventional and solar heating systems under tunnel tunisian greenhouses: Thermal performance and economic analysis," Solar Energy, vol. 120, pp. 620-635, 2015.

[21] M. Motevasel, A. R. Seifi, and T. Niknam, "Multi-objective energy management of chp (combined heat and power)-based micro-grid," Energy, vol. 51, pp. 123-136, 2013.

[22] F. Garcia and C. Bordons, "Optimal economic dispatch for renewable energy microgrids with hybrid storage using model predictive control," in Industrial Electronics Society, IECON 2013-39th Annual Conference of the IEEE. IEEE, 2013, pp. 7932-7937.

[23] G. Ferrari-Trecate, E. Gallestey, P. Letizia, M. Spedicato, M. Morari, and M. Antoine, "Modeling and control of co-generation power plants: a hybrid system approach," IEEE Transactions on Control Systems Technology, vol. 12, no. 5, pp. 694-705, 2004.

[24] R. Dufo-López, J. L. Bernal-Agustín, and J. Contreras, "Optimization of control strategies for stand-alone renewable energy systems with hydrogen storage," Renewable energy, vol. 32, no. 7, pp. 1102-1126, 2007.

[25] J. Löfberg, "Automatic robust convex programming," Optimization methods and software, vol. 27, no. 1, pp. 115-129, 2012. 